\title{
Arthur P. Wolf: Incest Avoidance and the Incest Taboos, Two Aspects of Human Nature
}

\section{Stanford Briefs, Stanford, CA, 2014, 178 pp, ISBN-13: 978-0804789677}

\section{Thomas O'Carroll ${ }^{1}$}

Published online: 27 November 2015

(C) The Author(s) 2015. This article is published with open access at Springerlink.com

Incest, for which there have traditionally been fearsome penalties in numerous cultures around the globe, has been claimed as the only universal taboo; but others insist that the practice-or perpetration-of incest is pervasive, and have fought passionately to destroy the social structures enabling it to thrive. One well-known essay is even called "The universality of incest" (my emphasis) (DeMause 1991).

Patriarchal domination has been theorised by feminists as a means by which men use sex as an instrument of power and control over women and children. Incest has been conceived as something fathers do because they can, if they are allowed to get away with it. Sexual desire and drive are often denied, or at least played down in this analysis to the point of invisibility. Incest between siblings (especially when they are adults) has been relatively marginalised as a focus of contemporary concern unless one of them, presumptively a brother, is perceived as abusing their power over a younger or weaker victim.

What this shift of emphasis towards power, and away from sexual desire, has somewhat obscured in recent times is the hitherto great and still unresolved debate begun over a century ago as to the origins and significance of the incest taboo. In particular, do we need a powerful taboo in order to hold destructive sexual desires at bay, as Freud maintained; or, as Westermarck held, is incest rare because most of us actually have very little appetite for it? If the Second Wave feminists who turned the spotlight on power were entirely right to demote sexual motivation (beyond a pressing political necessity to do so), the debate could now be seen as passé, resolving itself by irrelevance.

Thomas O'Carroll

tomocarr66@yahoo.co.uk

1 Cumbria, UK 
Well, the appetite for incest may or may not be great, but my guess is that we are still ravenous for a convincing account of it.

As a veteran field officer in the intellectual 100 years war over incest, anthropologist Arthur P. Wolf fired what was destined to be his final salvo with the publication of his book Incest Avoidance and the Incest Taboos: Two Aspects of Human Nature. He would die only months later, in May this year, at the age of 83 .

Even the title is provocative, with the taboos cast not as an aspect of culture but of nature. But it would be a mistake to be dismissive on this account. And because the error is so tempting, I feel moved to stay at once the hand that would impetuously hurl this volume towards the trash can. Its great virtue, I can declare without the slightest fear of contradiction, is the concise clarity with which its twin theses are presented. Love or loathe its conclusions, this slim volume unquestionably provides a hugely illuminating introduction to the issues and evidence, with counter-arguments scrupulously acknowledged—before being dispatched, it must be added, with what may seem disdainful brevity. This being a title in the Stanford Briefs series, though, the author was simply sticking to his remit.

The book addresses two questions, each neatly occupying half the allotted space, in sequence: Firstly, why is it that most people avoid sexual relations with their close kin (as they do, if the available research evidence is to be believed)? Secondly, why is it that they disapprove of other people's having sex with their close kin, thereby giving rise to the incest taboo?

The first question sees Wolf soon whisking us off to the remote Trobriand islands. As Malinowski discovered in the 1920s, the islanders enjoyed great freedom to engage in premarital sex but had incest taboos ranging from very strict to mild, depending on their position in the matrilineal kinship system: sex with a maternal cousin was considered terrible; but with a paternal one it was actually recommended for sexually inexperienced boys! Even father-daughter sexual contact was relaxed, as they were not regarded as strictly close kin: the father was seen as a sort of "in law". As evidence for the power of culture to shape our behaviour, trumping any innate disposition towards the avoidance of sexual relations with close "blood" kin, these "artificial" rules would appear decisive-to say nothing of making our definition of incest complex and problematic. Yet Wolf is what he calls a "constitutionalist" as opposed to a "conventionalist": innate disposition underpins his thinking. What makes his theory worthy of consideration is his strong attention to research evidence combined with a full recognition of cultural variability and the need to account for it without insult to its subtlety, depth and distinctive humanity.

The theme of kinship brings Wolf to G. P. Murdock's survey of kinship systems in the 1940s, which included eight generalisations about incest taboos, each of them discussed. Murdock claimed such taboos were universal except for "rare and highly restricted" exceptions. Among them are "royal incest" in a number of cultures, most famously in Ancient Egypt, Cleopatra being the progeny of a brother-sister union. In recent times it has been discovered that sibling marriages were widespread among all classes in Egypt during the Graeco-Roman period. Going beyond sibling unions, Verrier EIwin reported that in some endogamous Indian groups, such as the Baiga, incestuous marriage has been practised between men and their daughters, 
between women and their sons, between siblings, and even between grandparents and their grandchildren (EIwin 1939).

Modern western surveys show that incest between siblings, contrary to what power-abuse theory would logically predict, is far more prevalent than all the adultchild possibilities, including father-daughter and mother-son. However, the devil is in the detail of such studies. Incest as traditionally conceived has been sexual intercourse with a nubile female: father-daughter intercourse from which progeny could result, and mother-son intercourse of the same kind, are known to be far less common than intergenerational "child sexual abuse" within the nuclear family, which is now often taken to include any genital touching. This is in sharp contrast with, for example, some Inuit societies, and formerly in Bali, where mothers would routinely stroke the penises of their infant sons; such behaviour has been considered no more abusive or sexual than breast-feeding. On the other hand, definitions of incest can extend even to wet nurse foster mothers: so called "milk incest".

Wolf dismisses a number of superficial thoughts as to why incest with close kin is generally avoided. The "hygiene hypothesis" holds that consanguineous inbreeding has always been avoided because it can produce genetic defects. But this would not have been apparent to early humans: incest avoidance on these grounds could only have occurred automatically, through the differentially high survival of children born to non-incestuous partners, thereby generating an innate trait favouring outbreeding. It would not have been a conscious phenomenon, such as would have been necessary in order to produce a taboo.

Freud focused on what Wolf calls group harmony. In Totem and Taboo he took "Darwin's primal horde" as his starting point, a society in which "a violent and jealous father ... keeps all the females to himself and drives away his sons as they grow up". The incest taboo, in this account, originated when the sons united and killed their father. Overcome by guilt, they revoked their deed by resigning their claims to the women they had freed. A society which allowed incest, Freud concluded, could not develop a stable family.

But this was pure myth-making. As Wolf points out, the idea was based on many untested assumptions, notably that if it were not for the taboo most people would want to have sex with their close kin; that the jealousies thus engendered would destroy the family; and that, if this and all the other assumptions were true, our ancestors would have seen the danger and invented a prohibition as the solution.

Before Freud, Edward B. Tyler had focused on what Wolf calls group alliance. This refers to inter-group harmony, rather than the intra-group kind just discussed. He proposed that "marrying out" solved the problem of when tribes began to "press on one another and quarrel". Tyler wrote: "Again and again in the world's history, savage tribes must have had plainly before their minds the simple, practical alternatives between marrying-out and being killed out." Not so, says Wolf. While the policy described by Tyler might have had the effect in question, it would have required rational deliberation and powers of inter-community enforcement that would not have been available.

Another founding figure of these debates was Edward Westermarck. In 1891, this Finnish sociologist and anthropologist published The History of Human Marriage, a 
study running to a mighty 1544 pages. Its most lastingly contended legacy has come to be known as the Westermarck Hypothesis.

Wolf quotes his proposal that "our laws against incest are scarcely felt", for the simple reason that "in normal cases there is no desire for the acts which they forbid". This is because "generally speaking there is a remarkable absence of erotic feelings between persons living closely together from childhood". Kin reared apart, by contrast, are likely to interest one another sexually if they meet as adults.

Incompatible, it would seem, with Freud's psychodynamic view that families are a hotbed of powerful mutual desires that must be suppressed for the sake of harmony and stability, the Westermarck Hypothesis long fell out of favour with the ascendancy of Freud. Grounded as it was in the theory that incest avoidance is an evolved trait, working deep beneath the level of consciousness, the hypothesis was widely seen as offensive to human dignity and agency: it seemed to make us automatons, the slaves of our inherited appetites, not our moral choices. Freud had also thought of culture as a civilizing force, lifting humanity above savagery, acting as a brake on destructive incestuous desire.

Freud and Sir James Frazer had argued that you do not need a law or taboo against something if there is no inclination to do it anyway. Westermarck had what ought to have been considered a good answer to that. He suggested to Frazer that he could not possibility be "ignorant of the variability of instincts and of the great variability of the sexual instinct, nor the fact that there are circumstances in which a natural sentiment may be blunted or overcome". He pointed out that parricide and bestiality are also forbidden by law. It did not mean that without such laws and taboos everyone would be murdering their parents and coupling with beasts.

Wolf, during a career in which he almost single-handedly revived the status of the Westermarck Hypothesis, went beyond arguments. He looked for evidence, which he found in the work of others and through his own decades-long anthropological field investigations. Incest Avoidance and the Incest Taboos summarises these findings, centred on three natural experiments: (1) bint 'amm marriage in Morocco and elsewhere in the Islamic world; (2) Chinese hsaio-hun marriage ("little marriage" or "minor marriage"); (3) communal child rearing in Israeli kibbutzim.

Briefly, the partners in Moroccan-style and Chinese arranged marriages of couples brought up together as children tend to be unwilling spouses; extensive data from Taiwan also show that the Chinese marriages are characterised by high levels of divorce, and they have fewer children. Biologically unrelated children brought up together in Israel may have had sexual experiences together in childhood and adolescence but only very rarely did they grow up to have romantic relationships or marry each other.

Does the evidence hold up? It undoubtedly stands strong against a great many scholarly objections. This reviewer has seen only one truly formidable challenge, and it does not arise from any flaw in Wolf's own work. Instead, we now have data from some ingenious and impressively conducted psychological lab experiments that point in completely the opposite direction. Fraley and Marks (2010) reported three experiments, including one demonstrating that people find pictures of strangers more sexually attractive immediately after they have been subliminally 
exposed to an image of their own (the experimental subject's) opposite-sex parent. The authors also noted earlier research showing that even adopted children tend to have spouses who resemble their adoptive opposite-sex parent. Being brought up with, and indeed by, that person apparently increases rather than decreases (as would have been predicated by the Westermarck Hypothesis) the likelihood of someone like that person being chosen as a mate.

Fraley and Marks conclude by rejecting the Westermarck Hypothesis as to an unconscious innate (genetic) mechanism causing us to reject those we were brought up with as sexual partners. But they embrace the reality of the Westermark effect. They say:

We believe that one way to explain the Westermarck effect is via the process of habituation. Research indicates that sexual passions often wane as people become increasingly habituated to one another... As such, when people grow up, they may come to find that their playmates, siblings, and friends are less sexually appealing than they are relative to other people. At first glance, it may seem that this proposal is inconsistent with our previous argument that familiarity plays a role in facilitating sexual desire. There is an important distinction to be made, however, between familiarity that arises from conscious and unconscious sources.... it seems likely that familiarity enhances sexual desire when its origins are unknown. When the source of familiarity is obvious, however, as it is with siblings and playmates, familiarity will not necessarily have the same effects.

One can almost see King Oedipus himself nodding in rueful concurrence with that "unconscious sources" point.

Fraley and Marks depart from Freud's view of incest but their "evolutionary psychodynamic framework" finds a place for learning, culture and the resolution of interpersonal tensions in the shaping of our morality and behaviour:
According to an evolutionary psychodynamic framework, attraction for kin arises not because people harbor natural incestuous urges... but because the mechanisms that promote familiarity, bonding, and attraction are most likely to operate on inputs experienced in the early family environment. For example, if sexual imprinting... takes place in humans, then one's early interactions with primary attachment figures can play an influential role in shaping the "ideal" for what kinds of people one will find attractive... Specifically, one will be drawn toward others who resemble one's family members.

Whereas Wolf may be thought overly reductive, Fraley and Marks do not fall into the trap of boiling everything down to the unconscious playing out of simple evolved traits. Indeed, the approach taken by these two social psychologists, based as it is on an experimentally underpinned synthesis of evolutionary and psychodynamic factors, seems a more promising one for addressing incest avoidance than either Wolf's view or that of interesting but highly speculative commentators, such as Ingham and Spain (2005) and Paul (2010). Recent sociological research (Shor and Simchai 2009) has also greatly enriched our understanding and led, like Fraley 
and Marks, to a very welcome synthetic approach, drawing on both biologicalevolutionary perspectives and socio-cultural ones (Shor 2015).

Why we avoid incest it will be recalled, was the first of Wolf's two questions. The other was why it is taboo. In view of the now strongly rehabilitated Westermarck Effect, this second issue has become more urgently puzzling. An intense, emotionally felt prohibition against something that holds little temptation appears to make no sense.

Wolf's solution is again very simple. Nuclear family incest is rare; humans tend to react with instinctive distrust and fear towards unusual behaviour: it is "abnormal" and "deviant". That's it, pretty much. It is an elegantly parsimonious solution and one that this reviewer finds more persuasive in Wolf's telling than the Freudian alternative, or even than the later and also massively influential (but fatally flawed) theory developed by Claude Levi-Strauss based on his kin structure analysis (Lévi-Strauss 1949; Leach 1961).

Whether Wolf's solution is correct is another matter. He reminds us that twins are rare, like incest, and suggests that is why twin births are regarded with suspicion and hostility in some cultures, as an event foretelling misfortune. One might counter, though, that elsewhere the reaction is absolutely the opposite: this rare event is considered a blessing. Even unusual physical attributes that could easily be seen as defects, such as birth marks, or albinism, are sometimes venerated as a divine gift. The variation in such reactions could be attributable to any number of factors. In the case of twins, for instance, the cultural response can be expected to change over time as the demographic situation shifts: one would predict that where there is perceived under-population twins would be welcome; where over-population is a source of anxiety they would not.

Overall, Wolf's brisk, authoritative style is that of a scholar who is confident that after a lifetime's work, much of it spent fielding often rather weak criticism of his ideas, he has truly cracked the big questions about incest. In his final pages he rounds off with a neat 12-step summary of his argument that looks as precisely conclusive as a mathematical proof: Q.E.D.! In reality, such is the complexity of human affairs, including incestuous ones, that the great debate could easily last another 100 years or more.

\section{Compliance with ethical standards}

Ethical approval This article does not contain any studies with human participants or animals performed by any of the authors.

Open Access This article is distributed under the terms of the Creative Commons Attribution 4.0 International License (http://creativecommons.org/licenses/by/4.0/), which permits unrestricted use, distribution, and reproduction in any medium, provided you give appropriate credit to the original author(s) and the source, provide a link to the Creative Commons license, and indicate if changes were made.

\section{References}

DeMause, L. (1991). The universality of incest. Journal of Psychohistory, 19, 2.

EIwin, V. (1939). The Baiga. London: John Murray. 
Fraley, R. C., \& Marks, M. J. (2010). Westermarck, Freud, and the incest taboo: Does familial resemblance activate sexual attraction? Personality and Social Psychology Bulletin, 36(9), 1202-1212.

Ingham, J. M., \& Spain, D. H. (2005). Sensual attachment and incest avoidance in human evolution and child development. Journal of the Royal Anthropological Institute, 11(4), 677-701.

Leach, Edmund. (1961). Rethinking anthropology. London: Athlone Press.

Lévi-Strauss, C. (1949). The elementary structures of kinship. Boston: Beacon Press 1969.

Paul, R. A. (2010). Incest avoidance: Oedipal and pre-oedipal, natural and cultural. Journal of the American Psychoanalytic Association, 58(6), 1087-1112.

Shor, E. (2015). The Westermarck Hypothesis and the Israeli Kibbutzim: Reconciling contrasting evidence. Archives of Sexual Behavior, 44(8), 2139-2150.

Shor, E., \& Simchai, D. (2009). Incest avoidance, the incest taboo, and social cohesion: Revisiting Westermarck and the case of the Israeli Kibbutzim. American Journal of Sociology, 114(6), 1803-1842. 